\title{
PERSONALITY TRAITS OF BABY IN BABY DRIVER MOVIE
}

\author{
Prasetyo $^{1}$, Meisuri $^{2}$, Juli Rachmadani ${ }^{3}$ \\ ${ }^{123}$ UNIVERSITAS NEGERI MEDAN
}

\begin{abstract}
This study aimed at analyzing the kind of traits which represented by Baby in Baby Driver movie by Edgar Wright. The study of Characterization has been thrived in recent centuries. Personality Traits study in a movie is an interesting way to develop and identify some character in movies. The study used descriptive qualitative method. The data of this study were dialogues and statements from Baby which related to the Personality Traits theory in the movie script. The source of the data was Baby Driver movie. The findings of the Big Five theory analyzed by described the utterances and statements from Perlocutionary Act findings. It was found that there were five traits represented by Baby along the movie. They were (1) Introvert/Extrovert, (2) Neuroticism, (3) Conscientiousness, (4) Openness to Experience, and (5) Agreeableness. This study also proved that conflicts always happened in human being, especially teenager. At one time, a person chose to be introvert and in the next day he or she chose to be extrovert. Characterization learning was believed as a tool to differ one character of a movie or real-life individual from another.
\end{abstract}

Keywords: Personality Traits, Speech Act, Perlocutionary Act.

\section{INTRODUCTION}

Personality Traits and Character or characterization learning has been thrived around the globe in ancient civilizations. And it also has been studied for many years throughout centuries. From the Ancient Greek, Pharaoh, and many great civilization studied it to achieve some particular purposes. By learning characterization, winning the war could be achieved easily. For example, Pharaoh was great in conquering his enemies by political issues, learning the enemy, and hit them from the inside. With his cunning plans, he tore one nation apart in a second. It may have negativity and fearful attitudes with destructive results. Nowadays, character and characterization aren't supposed to be like that. By those learning, researchers always come up with the good result to determine past, present, and the future of the object of the study. While character and personality are both used to describe someone's behaviors, the two examine different aspects of that individual. One's personality is more visible, while one's character is revealed over time, through varying situations. Character and characterization developed throughout every part of life. By assessing one character, result may have varies and many possibility as the outcome in the process.

Character and Films can be combined as a study data. Since films deal with "movie 
characters", a clearer understanding about character personality can be identified here for the further application in real-life character. Eder (2010) stated that In today's media societies, the characters of films and other audiovisual media are important. They provoke questions about the meaning and effects from different forms of understanding. Filmmakers also discuss their creation, viewers, critics, interpretation, cultural theorist, and practitioners that related to their own films.

In a movies or films, sometimes characters also have character development from which the first part to the end part of the movie. For example, Baby in Baby Driver movie represented some major development throughout the movie. Especially for teenagers, "character shifting" happens all the time. By the sequences made by the Director Edgar Wright, Baby is a complete figure to be researched from the beginning to the end of the events that affected to him along the movie. As noted by Boyce and Wood (2015), personality is most often viewed within the five factor model (FFM by McCrae and Costa). The basic traits of agreeableness, conscientiousness, extraversion, neuroticism, and openness occupy the highest and lowest level of one individual to the psychological characteristics.

Byl (2016) conducted a research describing Humbert from a child to adult in Humbert Humbert movie. The process of his character shaped within mind and memory. Inside and outside factors affect the character's development in the story. Thus, this research analyzed by the data from main character, secondary characters, and each supporting characters in the novel. The writer used the intrinsic approach to analyze the interrelation between the characters in the characters in the novel that is to evaluate the characters by his words, what he is thinking and doing, and from what is the author said about them.

Another study that focused on characterization was conducted by Reams (2015) on "Characterization in Fiction". This research's goal was to examine the importance of characterization in fiction, as well as the methods of characterization itself. And he believed that believe that the methods of characterization in fiction can be examined and described through a combination of literary theory and analysis. At the end it will show that there is a certain order or logic to story writing. An underlying form, if you will, that can be understood and applied to stories.

By comparing some of the similar studies, the personality traits was chosen by the researcher, for it was necessarily important to determine one individual of Baby as a complete character that represented all the theory classification.

\subsection{Personality Traits}

The most influential personality research of the past few decades indicates that there are five basic personality traits. These are commonly known as "The Big Five". Five-Factor 
Theory, formulated by Robert (Jeff) McCrae and Paul Costa. It's an explanatory account of the role of the Big Five factors in personality. Five-Factor Theory includes a number of propositions about the nature, origins, and developmental course of personality traits and about the relation of traits to many of the other personality variables mentioned earlier. Five-Factor Theory presents a biological account of personality traits, in which learning and experience play little if any part in influencing the Big Five.

Soto (2018) describes personality traits learning as a characteristic pattern of thinking, feeling, or behaving that tends to be consistent over time and across relevant situations. The Big Five which are Extraversion, Agreeableness, Conscientiousness, Neuroticism and Openness to Experience are a set of five broad, bipolar trait dimensions that constitute the most widely used model of personality structure. A considerable body of research has examined personality stability and change across the life span, as well as the influence of personality traits on important life outcomes, in terms of the Big Five.

\subsubsection{Introversion/Extraversion}

Introversion/Extraversion define where a person energy is directed. Introversion means that the person's energy is directed inward. This could include being rigid, reliable, sober or controlled. In all these traits, energy is directed inward. Extraversion means that person's energy is directed out-ward. This could include being easy-going, lively or excitable, all traits in which energy are directed outward.

\subsubsection{Neuroticism}

Neuroticism is often associated with emotional stability. People with high neuroticism would be easily distracted, moody, easily stressed, irritable, and often worried. People with character like this would be very difficult to feel satisfied in their jobs. Most of them will work as forced. Meanwhile, people with low neuroticism will be more relaxed, calm, emotionally stable, and away from bad thoughts.

\subsubsection{Conscientiousness}

Conscientiousness is the degree of organization, self-control, and persistence a person shows in pursuing goals. Conscientiousness (high C) people tend to be hardworking, ambitious and driving. No conscientious (low C) people tend to be lazy, negligent, and pleasure-seeking.

\subsubsection{Openness to Experience}

Openness to experience is the degree to which a person actively seeks out an appreciates experiences for their own sake. On one end of the continuum, open (high $\mathrm{O}$ ) individual show curiosity, imagination, and some unconventionality in their values. They tend to experience emotions more vividly. Low O persons tend to be more conventional, conservative, and rigid in their beliefs and have diminished emotional responsiveness. 


\subsubsection{Agreeableness}

Agreeableness is a tendency to be compassionate and cooperative rather than suspicious and antagonistic towards others. The trait reflects individual differences in general concern for social harmony. Agreeable individual's value getting along with others. They are generally considerate, friendly, generous, helpful, and willing to compromise their interests with others. Agreeable people also have an optimistic view of human nature. They believe people are basically honest, decent, and trustworthy. Disagreeable individuals place self-interest above getting along with others. They are generally unconcerned with others' well-being, and are less likely to extend themselves for other people. Sometimes their skepticism about others' motives causes them to be suspicious, unfriendly, and uncooperative.

\subsection{Character and Characterization}

\subsubsection{Character}

A film could not be formed without a story in it. It also happen in story, story could not be called as a story without any characters in it. In literary works character and characterization are important elements because they build the story. In narrative or dramatic works it usually uses the term character and characterization.

Martin (2004) defines character has a number of connotations. He is speaking of stylistic and narrative techniques for the representation of human features, actions, intentions, desires and traits in the novel form and how these interact with reader's cognitive strategies for recognizing and developing knowledge (or the feeling of knowledge) about other people.

\subsubsection{Characterization}

For the basic, Reams (2015) defines characterization as any action by the author or taking place within a work that is used to give description of a character. In general, it is divided into direct and indirect characterization. Direct characterization is anything that the author tells directly to the reader. Indirect characterization is anything that is shown to the reader by another source. Taking it one step further, characterization can be conveniently separated into five primary categories: Physical description, Actions, Reactions, Thoughts, and Speech.

The process of creating and developing character in a work fiction is called characterization. Jones (2008) states Characterization is the depicting of clear images of a person. Characterization, by this definition, means the real description of the characters participating in the story through their actions.

\section{METHODOLOGY}

In accomplishing this research, the writer used descriptive qualitative method. This research was conducted by using descriptive qualitative method. The writer analyzed character from many aspects through the words, action, narrator, and description of another character. 
Thus, these aspects were analyzed through the words means and words from the script of the story. Every utterance of the main character also analyzed by using the related theory perlocutionary act by Searle. The main character's attitudes on acts indirectly indicated their personality and role.

The data are collected in this research must be analyzed. The writer uses descriptive qualitative design. There are steps as follow.

1. Transcribing the utterances and act from the script which were related to the Personality Traits Theory.

2. Listing the utterances and act of the main characater based on character which related to the theory.

\section{FINDINGS \& DISCUSSIONS}

The data were identified and classified into 5 categorizations, they were Intro/Extrovert, Neuroticism, Conscientiousness, Opennes to Experience, and Agreeableness. The data analysis can be seen in Table 1:

Table 1. Personality Traits Percentage

\begin{tabular}{llc}
\hline No & \multicolumn{1}{c}{ Personality Traits } & Percentage \\
\hline 1 & Introversion/Extraversion & $25 \%$ \\
2 & Neuroticism & $18 \%$ \\
3 & Conscientiousness & $16 \%$ \\
4 & Opennes to Experience & $21 \%$ \\
5 & Agreeableness & $20 \%$ \\
\hline
\end{tabular}

The discussion of the most traits which was Introvert/Extrovert influenced Baby in the movie himself. The conflicts within showed up from the first part to the last part of the movie. The percentage of the Introvert/Extrovert traits were Introvert $57 \%$ and Extrovert $43 \%$.

This study was aimed to find out types of personality traits in the dialogues, the realization centered from Baby in Baby Driver movie. Personality traits that can be found in the movie are Intro/Extraversion (25\%), Neuroticism (18\%), Conscientiousness (16\%), Openness (21\%), and Agreeableness (20\%). Each amount were varies and also had amount differently.

\section{CONCLUSIONS AND SUGGESTIONS}

After the data of Baby's dialogues had been analyzed, conclusion were drawn as follow. 1. The types of personality traits were represented by Baby in Baby Driver movie. They were Intro/Extrovert (25\%), Neuroticism (18\%), Conscientiousness (16\%), Openness to Experience (21\%), and Agreeableness (20\%).

2. Therefore each of personality traits was filtered by using the perlocutionary act from the speech act. Thus, from Representative, Directive, Commisive, Expressive, and Declarative, the writer used them to be a tool to know where to put each of the act and classify them into the Big 
Five Theory.

\section{REFERENCES}

Boyce, C. J. Wood, A. M. Powdthavee, D. (2015). Personality Change Following Unemployment. Manchester: Jounal of Applied Psychology.

Byl, J. J. (2016). Analisis Karakter Tokoh Utama Dalam Novel Lolita Karya Vladimir Nabokov. Manado: Universitas Sam Ratulangi.

Eder, J. (2010). Understanding Characters. Queensland: Berhahn Jounals.

Halonen, Jane S. and John W. Santrock. (1999). Psychology Contexts \& Applications. USA: The McGraw-Hill Companies.

Jones, E. (2008). Outline of Literature: Short Story, Story: Novel, and Poem. United States of America: The Macmilliam Company.

Martin, P. (2004). Characterization in the Novel : An Aesthetic of the Uncanny. Dublin: Dublin City University.

Ramrao, T. N. (2016). Film and Literature : An Overview. India: International Journal of Multidiciplinary Research.

Reams, J. (2015). Characterization in Fiction. Texas: Texas State University.

Santrock, J. W. (2004). Educational Psychology. New York: McGraw Hill Companies.

Soto, C. J. (2018). Big Five Personality Traits. Thousand Oak California: SAGE

Wellek, R. \& Warren, A. (2011). Theory of Literature. New York: Harcourt, Brace \& Company. 